\section{Kidney \\ Blood Pressure Research}

\title{
Can Aortic Elastic Parameters be Used for the Diagnosis of Volume Overload in Patients with End Stage Renal Disease
}

\author{
Muhammet R. Sayin ${ }^{\mathrm{a}} \quad$ Ibrahim Akpinar ${ }^{\mathrm{a}} \quad$ Mehmet A. Cetiner ${ }^{\mathrm{b}} \quad$ Turgut Karabag $^{\mathrm{a}}$ \\ Mustafa Aydina Ender Hurc Sait M. Dogan ${ }^{\mathrm{a}}$ \\ aBulent Ecevit University, School of Medicine, Department of Cardiology, Kozlu 67600, Zonguldak, \\ 'Karadeniz Eregli State Hospital, Department of Cardiology, Zonguldak, 'Bulent Ecevit University, School \\ of Medicine, Department of Nephrology, Kozlu 67600, Zonguldak
}

\section{Key Words}

End stage renal disease - Aortic elastic parameters - Volume overload $\cdot$ Body composition monitor • Bioimpedance spectroscopy

\begin{abstract}
Background: We aimed here to investigate hydration status by echocardiography in end stage renal disease (ESRD) patients. Methods: 25 ESRD patients [15 males; mean age: 54.0 \pm 16.6 years; 13 hemodialysis; 12 peritoneal dialysis] were considered eligible for this study. We also examined 29 healthy volunteers as a control group (17 males; mean age: $46.5 \pm 12.8$ years). Body composition analysis using the bioimpedance spectroscopy technique was performed for volume overload diagnosis. The ratio of extracellular water (ECW) to height was used as volume indices. The aortic elastic parameters were calculated by echocardiography. A correlation analyses was performed between the ratio of ECW to height indicating the volume overload and the aortic elastic parameters e.g. Aortic strain (AS), Aortic distensibility (AD) and Aortic stiffness index (ASI). Results: The ratio of ECW to height that indicates volume overload in ESRD patients was considerably higher than that in the control group $(10.25 \pm 1.98$ $\mathrm{L} / \mathrm{m}$ vs $8.66 \pm 1.22 \mathrm{~L} / \mathrm{m}, \mathrm{p}=0.001$ ). There was a negative correlation between the ratio of ECW to height and $\mathrm{AS}$ and $\mathrm{AD}$ and a positive correlation between the ratio of ECW to height and ASI. Conclusion: Given the importance of the diagnosis and follow up of volume overload, the results show that aortic elasticity measurements, being easy to perform and replicate, can be used for this purpose.
\end{abstract}




\section{Kidney Blood Pressure Research}

Kidney Blood Press Res 2012;36:268-277

\begin{tabular}{l|l}
\hline DOI: $10.1159 / 000343416$ & (C) 2012 S. Karger AG, Basel
\end{tabular}

Published online: November 26, 2012

www.karger.com/kbr

\section{Introduction}

Cardiovascular morbidity and mortality are higher in patients with end-stage renal disease (ESRD) compared to normal population [1]. ESRD is associated with a variety of alterations in cardiac structure and function, including left ventricular (LV) dilatation, hypertrophy, systolic and diastolic dysfunction as related to volume overload [2, 3]. Aortic stiffness is also increased in patients with ESRD [4] and known to be associated with adverse cardiovascular outcomes and increased mortality such as those mentioned above [3-5]. The diagnosis and control of volume overload are of high significance in ESRD patients. Echocardiography is an established technique to estimate the risk for cardiovascular complications and a guide for treatment in patients with chronic renal failure [1-3]. However, it is not used for the diagnosis and follow up of volume overload.

Bioimpedance spectroscopy (BIS) represents a different approach to the assessment of fluid status [6-8]. The Body Composition Monitor (BCM) (Fresenius Medical Care, Germany) is a BIS device for clinical use, validated by isotope dilution methods [9], and reference body composition methods [10], and has been used in hemodialysis (HD) [11-14] and peritoneal dialysis (PD) $[15,16]$.

We aimed here to compare hydration status, as measured with BCM , and aortic elastic parameters, as measured by echocardiography, in ESRD patients.

\section{Materials and Methods}

\section{Patients}

Twenty-five ESRD patients (15 males; mean age: $54.0 \pm 16.6$ years; $13 \mathrm{HD}$; $12 \mathrm{PD}$ ) were considered eligible for this study. All procedures followed were in accordance with the ethical standards of the responsible committee on human experimentation (institutional and national) and with the Helsinki Declaration of 1975, as revised in 2000.

Patients who were older than 18-years, on maintenance bicarbonate HD scheduled thrice weekly (12 hours/week) and prevalent patients undergoing PD for at least 6 months willing to participate in the study with a written informed consent were included. Exclusion criteria were the presence of pacemaker or defibrillator, artificial joints, pin or amputation, being scheduled for living donor renal transplantation, presence of serious life-limiting co-morbid situations, like malignancy, uncontrollable infection, end-stage cardiac, pulmonary, or hepatic disease, pregnancy or lactating.

We also examined 29 volunteers which were choosen randomly with normal renal function as a control group (17 males; mean age: $46.5 \pm 12.8$ years). Basic demographic data were collected for both study groups, including age, gender, presence of diabetes and the presence of traditional major cardiovascular risk factors (age, sex, hypertension, dyslipidemia, body mass index, and current smoking), and the year when the patient started dialysis. Patients were considered to have hypertension if they had previously known hypertension, or if they were on antihypertensive therapy, or if they had a systolic blood pressure of $\geq 140 \mathrm{mmHg}$ and a diastolic blood pressure of $\geq 90 \mathrm{mmHg}$, which were calculated as the mean of two measurements taken on each arm. All volunteers underwent standard 2D M-mode and Doppler echocardiography and standard 12-derivation electrocardiogram.

\section{Measurements}

Measurement of overhydration. BIS was measured with the BCM from Fresenius Medical Care, Deutschland GmbH. Electrodes were placed on the right hand and foot on the site contra lateral to the arteriovenous fistula for HD patients midweek interdialytic day and in the morning with an empty abdomen for PD patients [17] with supine position. Two electrodes were dorsally placed on the hand in the metacarpophalangeal articulations and in the corpus, respectively, $5 \mathrm{~cm}$ apart. The pair on the foot was located in the metatarso-phalangeal and in the articulation, $6 \mathrm{~cm}$ apart. The BCM analyses total body electrical impedance to an alternate current $(0.2 \mathrm{~mA})$ with fifty different frequencies $(5-1000 \mathrm{kHz})$. The volume of extracellular water (ECW) is calculated from electrical resistances determined by BCM. The ratio of ECW to height was used as volume indices. 


\section{Kidney \\ Blood Pressure Research}

Kidney Blood Press Res 2012;36:268-277

\begin{tabular}{l|l}
\hline DOI: $10.1159 / 000343416$ & C 2012 S. Karger AG, Basel
\end{tabular}

Published online: November 26, 2012

www.karger.com/kbr

Sayin/Akpinar/Cetiner/Karabag/Aydin/Hur/Dogan: Aortic Stiffness Predicts Volume Overload in Renal Failure

Echocardiographic examination. Standard echocardiographic examinations were performed using a Vingmed Vivid System 5 (General Electric, Horten, Norway) device. A 2.5 MHz probe and a 2.5-3.5 MHz probe was used for the Doppler measurements and for tissue Doppler measurements respectively. All measurements were averaged from three cardiac cycles. 2D echocardiographic measurements were performed according to the standards outlined by the American Society of Echocardiography [18]. LV dimensions and wall thickness were obtained from the parasternal long axis with an M-mode cursor positioned just beyond the mitral leaflet tips, perpendicular to the long axis of the ventricle. LV end-diastolic diameter (LVEDD) and end-systolic (LVESD) diameter, thickness of the interventricular septum (IVS) and posterior wall of the left ventricle (PW) were measured. LV ejection fraction was calculated according to the Simpson method [19]. Mitral inflow velocities were evaluated by pulse-wave Doppler echocardiography with the sample volume placed at the tip of the mitral leaflets from the apical four-chamber view. Diastolic peak early (E) and peak late (A) transmittal flow velocity, peak E to peak A velocities (E/A), and deceleration time of peak E velocity (EDT) were measured.

The LV-pulsed tissue Doppler imaging (TDI) was performed in the apical four-chamber view using a 5 -mm pulsed Doppler sample volume with as minimum optimal gain as possible to obtain the best signalto-noise ratio. Care was taken to align the echo image so that the annular motion was parallel to the TDI cursor. Spectral pulsed wave Doppler signal filters were adjusted until a Nyquist limit of $15-20 \mathrm{~cm} / \mathrm{s}$ was reached. The monitor sweep speed was set at $50-100 \mathrm{~mm} / \mathrm{s}$ to optimize the spectral display of myocardial velocities. The sample volume was placed at the junction of the LV wall and the septal annulus from the fourchamber view sequentially. The myocardial peak early $(\mathrm{Em})$ velocities were obtained from the septum of the left ventricle. All echocardiographic measurements were performed by the same observer. The ratio of E/ Em for septal segment was measured. While echocardiographic examination was performed to obtain blood pressure data required to calculate the aortic elastic parameters, systolic blood pressure (SBP) and diastolic blood pressure (DBP) were measured simultaneously using a mercury sphygmomanometer and heart rate was simultaneously recorded by an electrocardiogram. All the measurements were performed at midweek interdialytic day for HD patients, and in the morning with an empty abdomen for PD patients.

\section{Aortic elasticity}

The parasternal long axis view was modified and the ascending aorta was monitored. M-mode echocardiographic tracings of the aorta were recorded at a level of $3 \mathrm{~cm}$ above the aortic valve. From the tracings recorded, systolic diameter of the ascending aorta (AoS) and diastolic diameter of the ascending aorta (AoD) were obtained. AoS was measured at the time of the full opening of the aortic valve and AoD was measured at the peak of QRS. At least three subsequent measurements were performed for each participant and the average of these measurements was calculated. The indices of aortic elastic properties, aortic strain (AS), aortic distensibility (AD) and aortic stiffness index (ASI), were calculated using the following formula [20]:

Aortic Strain $(\%)=100 \times(A o S-A o D) / A o D$

Aortic Distensibility $\left(\mathrm{cm}^{2} \times\right.$ dyn $\left.^{-1} \times 10^{-6}\right)=(2 \times$ Aortic Strain $) /($ SBP-DBP $)$

Aortic Stiffness Indeks $=\ln (\mathrm{SBP} / \mathrm{DBP}) /(\mathrm{AoS}-\mathrm{AoD}) / \mathrm{AoD}$

\section{Statistical analysis}

Statistical analysis was conducted using the Statistical Package for the Social Sciences (SPSS) for Windows (version 15; SPSS Inc., Chicago, IL, USA). The quantitative variables of the study were expressed as mean and standard deviation. Categorical variables were recorded using frequency and percentage. ROC (Receiver Operating Characteristic) curve analysis was used to determine the best cutoff points for the best value that can distinguish between the cases with and without volume overload. To determine the differences between the two groups, variables were evaluated using the Mann-Whitney U-test. Spearman's correlation analysis was performed to examine the relationship between continuous variables and outcomes. In this study, a p-value of $<0.05$ was considered to be statistically significant.

\section{Reproducibility}

Intraobserver variability was calculated as the difference in two measurements of the same patient by one observer divided by the mean value. Intraobserver variability was less than $5 \%$ for all aortic elasticity measurements. 


\section{Kidney Blood Pressure Research}

Sayin/Akpinar/Cetiner/Karabag/Aydin/Hur/Dogan: Aortic Stiffness Predicts Volume Overload in Renal Failure Table 1: Clinical
and demographic
parameters
Table 2: Bioimpedance, bioche-mical and echocardiographic parameters

\begin{tabular}{lccc}
\hline & Patients $(\mathrm{n}=25)$ & Controls $(\mathrm{n}=29)$ & $\mathrm{p}$ \\
\hline Age (years) & $54.0 \pm 16.6$ & $46.5 \pm 12.8$ & $\mathrm{NS}$ \\
Male (n) & 15 & 17 & NS \\
BMI $\left(\mathrm{kg} / \mathrm{m}^{2}\right)$ & $26.51 \pm 6.59$ & $27.19 \pm 3.27$ & NS \\
HT (n) & 13 & 8 & NS \\
DM (n) & 11 & 6 & NS \\
DL (n) & 3 & 1 & NS \\
Smoking (n) & 3 & 5 & NS \\
SBP (mmHg) & $139.4 \pm 28.9$ & $127.5 \pm 13.8$ & NS \\
DBP (mmHg) & $72.6 \pm 13.9$ & $76.1 \pm 7.11$ & NS \\
HR $(1 / \mathrm{min})$ & $79 \pm 12$ & $75 \pm 10$ & NS \\
eGFR (mL/min $\left./ 1.73 \mathrm{~m}^{2}\right)$ & $6.5 \pm 2$ & $79 \pm 18$ & $\mathrm{p}<0.001$ \\
\hline
\end{tabular}

BMI: Body mass index, HT: Hypertension, DM: diabetes mellitus. DL: dyslipidemia, SBP: Systolic blood pressure, DBP: Diastolic blood pressure, HR: Heart rate, eGFR: Estimated glomerular filtration rate

\begin{tabular}{lccc}
\hline & Patients $(\mathrm{n}=25)$ & Controls $(\mathrm{n}=29)$ & $\mathrm{p}$ \\
\hline IVS $(\mathrm{cm})$ & $1.19 \pm 0.28$ & $0.98 \pm 0.11$ & $\mathrm{p}<0.001$ \\
PW $(\mathrm{cm})$ & $1.19 \pm 0.26$ & $1.01 \pm 0.11$ & $\mathrm{p}=0.002$ \\
LVEDD $(\mathrm{cm})$ & $4.69 \pm 0.70$ & $4.64 \pm 0.26$ & $\mathrm{NS}$ \\
LVESD $(\mathrm{cm})$ & $2.72 \pm 0.53$ & $2.71 \pm 0.34$ & $\mathrm{NS}$ \\
LA $(\mathrm{cm})$ & $3.85 \pm 0.65$ & $3.53 \pm 0.31$ & $\mathrm{p}=0.006$ \\
AOS $(\mathrm{cm})$ & $3.27 \pm 0.48$ & $3.03 \pm 0.38$ & $\mathrm{p}=0.035$ \\
AOD $(\mathrm{cm})$ & $3.14 \pm 0.51$ & $2.81 \pm 0.41$ & $\mathrm{p}=0.01$ \\
AS $(\%)$ & $4.46 \pm 2.84$ & $8.32 \pm 3.73$ & $\mathrm{p}<0.001$ \\
AD $\left(\mathrm{cm}^{2} \times \mathrm{dyn}^{-1} \times 10^{-6}\right)$ & $1.76 \pm 1.64$ & $3.42 \pm 1.86$ & $\mathrm{p}<0.001$ \\
ASI & $3.96 \pm 0.79$ & $3.10 \pm 0.47$ & $\mathrm{p}<0.001$ \\
EDT (ms) & $268 \pm 55$ & $216 \pm 57$ & $\mathrm{p}=0.002$ \\
E/A & $0.93 \pm 0.41$ & $1.28 \pm 0.43$ & $\mathrm{p}=0.001$ \\
E/E' & $13.8 \pm 4.37$ & $9.49 \pm 2.16$ & $\mathrm{p}<0.001$ \\
EF $(\%)$ & $58.7 \pm 5.5$ & $61.0 \pm 3.1$ & $\mathrm{NS}$ \\
Creatinin (mg/dl) & $8.79 \pm 2.20$ & $1.02 \pm 0.17$ & $\mathrm{p}<0.001$ \\
ECW/H $(\mathrm{L} / \mathrm{m})$ & $10.25 \pm 1.98$ & $8.66 \pm 1.22$ & $\mathrm{p}=0.001$ \\
\hline
\end{tabular}

IVS: interventricular septum, PW: posterior wall thickness, LVEDD: left ventricular enddiastolic diameter, LVESD: left ventricular end-systolic diameter, LA: left atrium, AOS: systolic diameter of the ascending aorta, AOD: diastolic diameter of the ascending aorta, AS: aortic strain, AD: aortic distensibility, ASI: aortic stiffness index, EDT: mitral E wave deceleration time, E/A: mitral diastolic E wave/ mitral diastolic A wave, E/E': mitral diastolic E wave / septal Ewave, EF: ejection fraction, ECW/H: extracellular water/height

\section{Results}

The clinical characteristics and demographics of the patient and control groups were similar except for renal functions (Table 1). Table 2 compares bioimpedance, biochemical and echocardiographic data. The mean vintage of dialysis was $3.76 \pm 2.31$ years for HD patients and $4.71 \pm 2.81$ years for PD patients. ESRD patients had higher left atrial and aortic diameters as compared to the control group $(3.85 \pm 0.65 \mathrm{~mm}$ vs $3.53 \pm 0.31, \mathrm{p}=0.006$ and $3.27 \pm 0.48$ vs $3.03 \pm 0.38, p=0.035$ ). Both groups had normal LV ejection fraction. The patient group had lower values for aortic strain and aortic distensibility and higher aortic stiffness index as compared to the control group (Table 2). Moreover, LV diastolic dysfunction was found in the patient group (E/A was $0.93 \pm 0.41$ and $\mathrm{E} / \mathrm{E}^{\prime}$ was $13.8 \pm 4.37$ ). In the patient group, clinical, demographic, bioimpedance, biochemical and echocardiographic parameters of the patients undergoing HD and PD were almost same. (Table 3). The HD group only had greater end systolic and end diastolic aortic diameters as compared to the PD group.

The ratio of ECW to height that indicates volume overload in ESRD patients was considerably higher than that in the control group $(10.25 \pm 1.98 \mathrm{~L} / \mathrm{m}$ vs $8.66 \pm 1.22 \mathrm{~L} / \mathrm{m}$, $\mathrm{p}=0.001)$. ROC analysis was performed to determine the threshold value that can predict volume overload. In the ROC curve analysis, sensitivity and specificity were $76 \%$ and $75.9 \%$, respectively, when an ECW/H ratio cutoff point of 9.44 was used to distinguish between the groups with and without volume overload (Fig. 1). A correlation analysis was performed 


\section{Kidney \\ Blood Pressure Research}

Kidney Blood Press Res 2012;36:268-277

\begin{tabular}{l|l}
\hline DOI: $10.1159 / 000343416$ & C 2012 S. Karger AG, Basel
\end{tabular}

Published online: November 26, 2012

www.karger.com/kbr

Sayin/Akpinar/Cetiner/Karabag/Aydin/Hur/Dogan: Aortic Stiffness Predicts Volume Overload in Renal Failure

Table 3: Data of the patient group

\begin{tabular}{|c|c|c|c|}
\hline & HD $(n=13)$ & $\mathrm{PD}(\mathrm{n}=12)$ & $P$ \\
\hline Age (years) & $60.5 \pm 14.5$ & $47.0 \pm 16.5$ & NS \\
\hline Dialysis vintage (years) & $3.76 \pm 2.31$ & $4.71 \pm 2.81$ & NS \\
\hline Male (n) & 10 & 5 & NS \\
\hline BMI $\left(\mathrm{kg} / \mathrm{m}^{2}\right)$ & $23.7 \pm 3.6$ & $27.2 \pm 9.8$ & NS \\
\hline $\mathrm{HT}(\mathrm{n})$ & 8 & 5 & NS \\
\hline $\mathrm{DM}(\mathrm{n})$ & 7 & 4 & NS \\
\hline $\mathrm{DL}(\mathrm{n})$ & 0 & 3 & NS \\
\hline Current smoker (n) & 2 & 1 & NS \\
\hline SBP (mmHg) & $145.3 \pm 29.5$ & $133.0 \pm 27.9$ & NS \\
\hline DBP (mmHg) & $72.0 \pm 11.8$ & $73.4 \pm 16.4$ & NS \\
\hline $\operatorname{HR}(1 / \mathrm{min})$ & $76 \pm 11$ & $81 \pm 13$ & NS \\
\hline IVS (mm) & $1.23 \pm 0.30$ & $1.15 \pm 0.27$ & NS \\
\hline $\mathrm{PW}(\mathrm{cm})$ & $1.23 \pm 0.30$ & $1.14 \pm 0.23$ & NS \\
\hline LVEDD $(\mathrm{cm})$ & $4.73 \pm 0.35$ & $4.64 \pm 0.97$ & NS \\
\hline LVESD $(\mathrm{cm})$ & $2.83 \pm 0.40$ & $2.60 \pm 0.64$ & NS \\
\hline $\mathrm{LA}(\mathrm{cm})$ & $4.07 \pm 0.62$ & $3.63 \pm 0.64$ & NS \\
\hline $\operatorname{AOS}(\mathrm{cm})$ & $3.50 \pm 0.33$ & $3.03 \pm 0.51$ & $\mathrm{p}=0.008$ \\
\hline $\mathrm{AOD}(\mathrm{cm})$ & $3.37 \pm 0.36$ & $2.90 \pm 0.55$ & $\mathrm{p}=0.03$ \\
\hline AS (\%) & $4.23 \pm 2.50$ & $4.71 \pm 3.2$ & NS \\
\hline $\mathrm{AD}\left(\mathrm{cm}^{2} \times \mathrm{dyn}^{-1} \times 10^{-6}\right)$ & $1.43 \pm 1.17$ & $2.1 \pm 2.04$ & NS \\
\hline ASI & $4.03 \pm 0.74$ & $3.88 \pm 0.86$ & NS \\
\hline $\mathrm{EDT}(\mathrm{ms})$ & $269 \pm 66$ & $268 \pm 43$ & NS \\
\hline $\mathrm{E} / \mathrm{A}$ & $0.91 \pm 0.41$ & $0.95 \pm 0.42$ & NS \\
\hline $\mathrm{E} / \mathrm{E}^{\prime}$ & $14.05 \pm 5.47$ & $13.54 \pm 2.97$ & NS \\
\hline $\mathrm{EF}(\%)$ & $57.6 \pm 5.4$ & $59.8 \pm 5.7$ & NS \\
\hline Creatinin (mg/dl) & $8.16 \pm 2.15$ & $9.48 \pm 2.14$ & NS \\
\hline $\mathrm{ECW} / \mathrm{H}(\mathrm{L} / \mathrm{m})$ & $10.30 \pm 2.57$ & $10.21 \pm 1.35$ & NS \\
\hline
\end{tabular}

BMI: Body mass index, HT: Hypertension, DM: diabetes mellitus. DL: dyslipidemia, SBP: Systolic blood pressure, DBP: Diastolic blood pressure, HR: Heart rate, IVS: interventricular septum, PW: posterior wall thickness, LVEDD: left ventricular enddiastolic diameter, LVESD: left ventricular end-systolic diameter, LA: left atrium, AOS: systolic diameter of the ascending aorta, AOD: diastolic diameter of the ascending aorta, AS: aortic strain, AD: aortic distensibility, ASI: aortic stiffness index, EDT: mitral E wave deceleration time, E/A: mitral diastolic E wave/ mitral diastolic A wave, E/E': mitral diastolic E wave / septal Ewave, EF: ejection fraction, ECW/H: extracellular water/height

Fig. 1. ROC (Receiver Operating Characteristic) curve analysis of the patients group for determine the threshold value that can predict volume overload.

between the ratio of ECW to height indicating the volume overload and the aortic elastic parameters AS, AD and ASI. There was a negative correlation between the ratio of ECW to height and AS and AD and a positive correlation between the ratio of ECW to height and ASI in patient group (Table 4). However, there was a positive correlation between the ratio of ECW to height and AS and $\mathrm{AD}$ and a negative correlation between the ratio of ECW to height and ASI in control group (Table 4, Fig. 2).

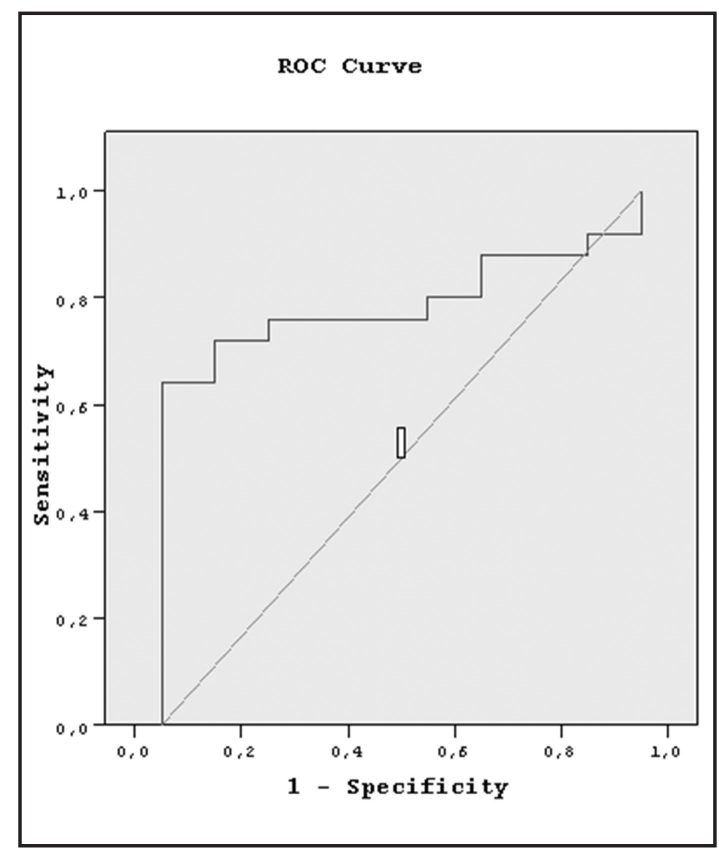




\section{Kidney \\ Blood Pressure Research}

Kidney Blood Press Res 2012;36:268-277

\begin{tabular}{l|l}
\hline DOI: $10.1159 / 000343416$ & (c) 2012 S. Karger AG, Basel
\end{tabular}

Published online: November 26, 2012

www.karger.com/kbr

Stinginar/Cetiner/Karabag/Aydin/Hur/Dogan: Aortic Stiffness Predicts Volume Overload in Renal Failure
Table 4: Spearman's correlation analysis with the ratio of ECW to height

\begin{tabular}{lcccc}
\hline & \multicolumn{2}{c}{ Patients } & \multicolumn{2}{c}{ Controls } \\
\cline { 2 - 5 } & $\mathrm{R}$ & $\mathrm{P}$ & $\mathrm{R}$ & $\mathrm{P}$ \\
\hline AS $(\%)$ & -0.628 & 0.001 & 0.496 & 0.006 \\
AD $\left(\mathrm{cm}^{2} \mathrm{x} \mathrm{dyn}^{-1} \times 10^{-6}\right)$ & -0.613 & 0.001 & 0.595 & 0.001 \\
ASI & 0.630 & 0.001 & -0.594 & 0.001 \\
\hline AS: aortic strain, AD: aortic distensibility, ASI: aortic \\
stiffness index
\end{tabular}

\section{Discussion}

The aorta plays an important role in the physiology of cardiovascular system. One of the most important physiological roles of the aorta is the capability to store blood ejected by the heart and to transfer this storage into the peripheral circulation during systole (Windkessel function) [21]. Elastic properties of the aorta play a major role at this point. Aortic stiffness indicates impaired elastic properties of the aorta [22]. Aortic stiffness is increased in patients with end-stage renal disease [4] and known to be associated with adverse cardiovascular outcomes and increased mortality [5]. Aortic stiffness is regarded as an important parameter reflecting early changes in vascular structure [23]. The mechanisms and time frames for the development of arterial stiffness in ESRD patients are unclear but may include traditional cardiovascular risk factors such as dyslipidemia and hypertension. Increased stiffness was shown to be largely influenced by the vascular calcifications [4]. Studies evaluating vascular calcification in ESRD patients showed that vascular calcification is an active process like atherosclerosis, and related with trans-differentiation of vascular smooth muscle cells to osteoblast/osteocyte-like cells, activation of osteoblastic transcription factors, and expression of bone matrix proteins $[24,25]$. Other potential pathophysiological mechanisms by which renal dysfunction increases aortic stiffness include the detrimental effect of oxidative stress and inflammation, as well as elevated plasma levels of asymmetric dimethylarginine and homocysteine on endothelial function [26]. Chronic volume overload may also induce alterations of mechanical forces and lead to changes in the geometry and composition of the vessel walls in ESRD patients. [27]. In this study, the aortic elastic parameters, AS and AD, were lower and ASI was higher in ESRD patients as compared to the control group, which is consistent with the literature.

Achieving a normal hydration state is one of the primary objectives in HD and PD treatments. The abnormal state of overhydration has been related to arterial hypertension, signs and symptoms of pulmonary and peripheral oedema, heart failure, left ventricular hypertrophy, and other adverse cardiovascular effects [28]. It has also been shown to be likely to cause arterial stiffness in this study. It was described that hydration state is an important independent predictor for mortality in chronic HD patients [11]. Therefore, the diagnosis and control of volume overload are of high importance in ESRD patients. In ESRD patients, the "gold standard" methods for measuring body water, such as deuterium (total body water) and sodium bromide (extracellular water), are laborious and cannot be used in clinical practice [29]. In most centers, the dry weight is determined based on clinical findings and is defined as the lowest weight a patient can tolerate without the development of symptoms such as hypotension, and cramp, which are complications experienced during dialysis. However, this method may not always yield reliable results that can guide treatment. Bioelectrical impedance analysis is a promising method for the objective assessment and monitoring of hydration in patients on ESRD. Whole-body bioimpedance spectroscopy has been shown to be as precise as the gold standard reference methods. The combination of this technology with the BCM model described in Chamney et al. [30] allows for the first time a target normohydration to be calculated. In this study, the ratio of ECW to height was used

Fig. 2. Scatter plots of the correlation analysis between the ECW/H ratio and aortic elastic parameters in both patient and control groups. 

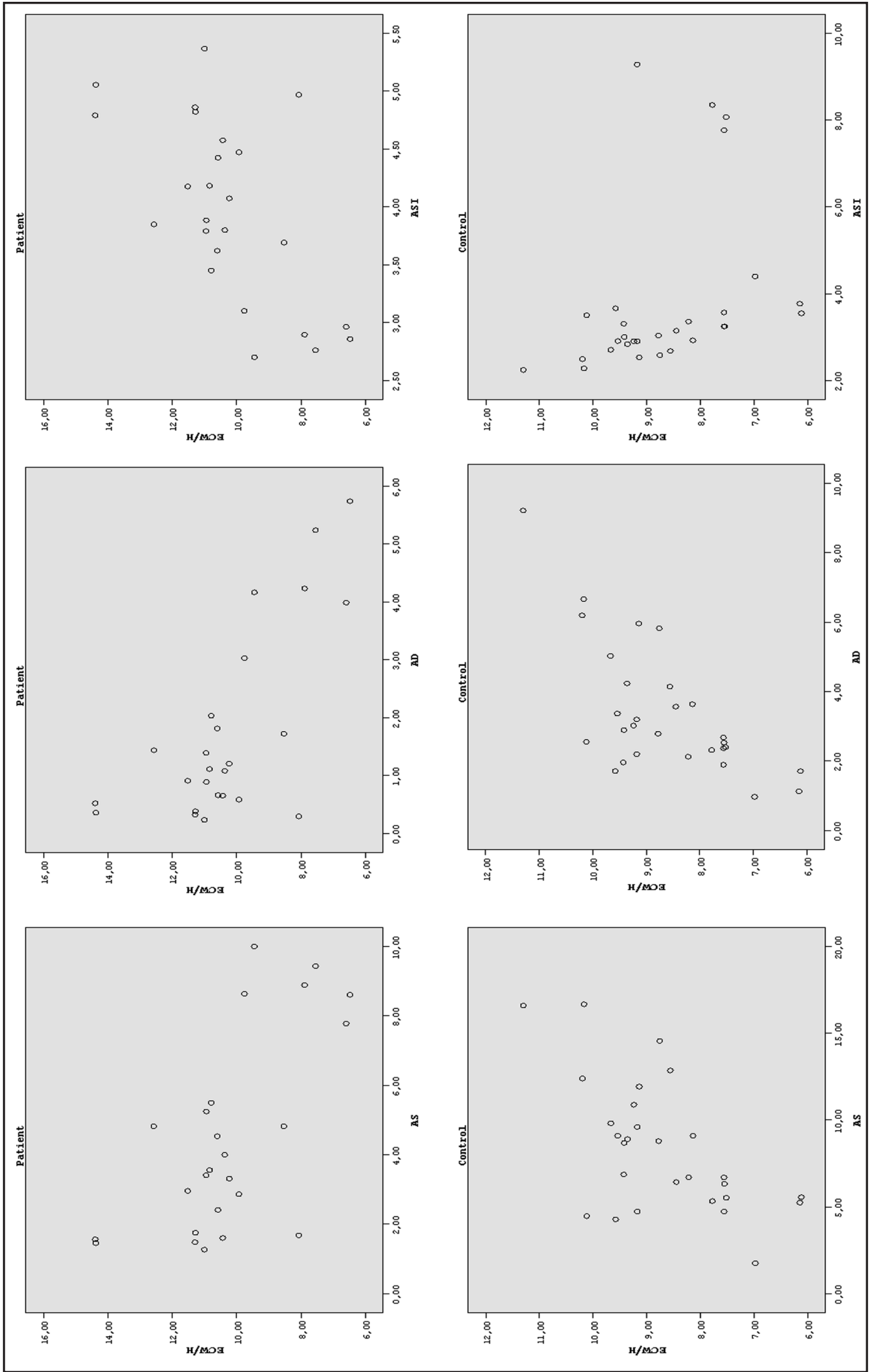


\section{Kidney Blood Pressure Research}

Kidney Blood Press Res 2012;36:268-277

\begin{tabular}{l|l}
\hline DOI: $10.1159 / 000343416$ & (C) 2012 S. Karger AG, Basel
\end{tabular}

Published online: November 26, 2012

www.karger.com/kbr

Sayin/Akpinar/Cetiner/Karabag/Aydin/Hur/Dogan: Aortic Stiffness Predicts Volume Overload in Renal Failure

for the detection of volume overload since the increased volume does not affect intracellular water but only ECW. Previously, it was shown that the ratio of ECW to height measured by bioimpedance could be used as a volume parameter and was increased in ESRD patients [15]. In the present study, the ratio of ECW to height was higher in ESRD patients as compared to the control group, which indicates volume overload in the patient group.

A decrease in AS and AD and an increase in ASI indicate impaired aortic elastic functions. In our study, volume overload was found to be negatively correlated with AS and AD and a positive correlation was found between volume overload and ASI in the group of patients with impaired aortic elastic functions. In the control group with preserved aortic elastic functions AS and AD were increased, while ASI was decreased. This inverse relationship found in the patient and control groups was considered to be caused by the difference in aortic elastic properties. In individuals without impairment in elastic functions, increased volume causes stretching of arterial walls, resulting in an increase in AS and AD and a decrease in ASI by affecting aortic diameters without influencing pulse pressure significantly (since adequate stretching occurs in systole). In patients with end-stage renal disease, however, since the elastic functions are impaired and due to arterial stiffness, increased volume will not cause a difference in the aortic diameters (due to inadequate stretching during systole) and will lead to an increase in the pulse pressure. This in turn will lead to impairment in aortic elastic parameters (decrease in AS and AD and increase in ASI).

\section{Study Limitations}

Several limitations of this study should be concerned. First, the most important limitation of this study was the small number of patients. Secondly, invasive techniques were not used to assess blood pressure. Blood pressure was measured by cuff sphygmomanometry of the brachial artery. However, Stefanadis et al showed that aortic stiffness determined by the echocardiographic method was closely related to that obtained by directly invasive measurements and suggested that aortic distensibility could be obtained noninvasively with a high degree of accuracy [32]. Additionally, we used indirectly measured brachial artery blood pressure instead of intraaortic pressure for the calculation of stiffness and distensibility indices. In the same study, there was a high correlation between aortic and brachial blood pressures [32]. Another limitation is that aortic elastic parameters are affected by many factors. In the evaluation of the patient, it may be difficult to determine whether impaired aortic elastic parameters are caused by volume load or additional comorbid causes. Therefore, it may be more useful in the follow-up of diagnosed volume overload. Furthermore, this study is of cross sectional design. We did not investigate the effects of the control of volume overload on aortic elasticity in the long term. Further long term studies with large patient populations are warranted.

\section{Conclusion}

In this study, a relationship was found between volume overload and aortic elastic parameters, an important indicator of cardiovascular adverse events, which suggests that volume overload is one of the causes of aortic stiffness and that the control of volume overload can prevent aortic stiffness. The major cause of death in ESRD patients is cardiovascular disease [31] and volume overload is an important cause of adverse cardiovascular events [28]. Thus, a strict follow up of volume overload is of high importance in ESRD patients. As volume overload increases so does aortic stiffness. Though being a result of volume overload, aortic stiffness can be used as an indicator of volume overload. Given the importance of the diagnosis and follow up of volume overload, the results show that aortic elasticity measurements, being easy to perform and replicate, can be used for this purpose. 


\section{Kidney \\ Blood Pressure Research}

Conflict of Interests
Kidney Blood Press Res 2012;36:268-277

\begin{tabular}{l|l}
\hline DOI: $10.1159 / 000343416$ & (C) 2012 S. Karger AG, Basel
\end{tabular}

Published online: November 26, 2012

www.karger.com/kbr

\section{References}

1 K/DOQI Workgroup: K/DOQI clinical practice guidelines for cardiovascular disease in dialysis patients. Am J Kidney Dis 2005;45:S1-S153.

-2 Foley RN, Parfrey PS, Harnett JD, Kent GM, Martin CJ, Murray DC, Barre PE: Clinical and echocardiographic disease in patients starting endstage renal disease therapy. Kidney Int 1995;47:186-192.

-3 Harnett JD, Foley RN, Kent GM, Barre PE, Murray D, Parfrey PS: Congestive heart failure in dialysis patients: prevalence, incidence, prognosis and risk factors. Kidney Int 1995;47:884-890.

-4 London GM, Guerin AP, Marchais SJ, Pannier B, Safar ME, Day M, Metivier F: Cardiac and arterial interactions in end-stage renal disease. Kidney Int 1996;50:600-608.

-5 Guerin AP, Blacher J, Pannier B, Marchais SJ, Safar ME, London GM: Impact of aortic stiffness attenuation on survival of patients in end-stage renal failure. Circulation 2001;103:987-992.

-6 Kraemer M, Rode C, Wizemann V: Detection limit of methods to assess fluid status changes in dialysis patients. Kidney Int. 2006;69:1609-1620.

7 Matthie JR: Bioimpedance measurements of human body composition: critical analysis and outlook. Expert Rev Med Devices 2008;5:239-261.

$>8$ Jaffrin MY, Morel H: Body fluid volumes measurements by impedance: A review of bioimpedance spectroscopy (BIS) and bioimpedance analysis (BIA) methods. Med Eng Phys 2008;30:1257-1269.

-9 Moissl UM, Wabel P, Chamney PW, Bosaeus I, Levin NW, Bosy-Westphal A, Korth O, Müller MJ, Ellegård L, Malmros V, Kaitwatcharachai C, Kuhlmann MK, Zhu F, Fuller NJ: Body fluid volume determination via body composition spectroscopy in health and disease. Physiol Meas 2006;27:921-933.

$\checkmark 10$ Wabel P, Chamney P, Moissl U, Jirka T: Importance of whole-body bioimpedance spectroscopy for the management of fluid balance. Blood Purif 2009;27:75-80.

-11 Wizemann V, Wabel P, Chamney P, Zaluska W, Moissl U, Rode C, Malecka-Masalska T, Marcelli D: The mortality risk of overhydration in haemodialysis patients. Nephrol Dial Transplant 2009;24:1574-1579.

12 Wizemann V, Rode C, Wabel P: Whole-body spectroscopy (BCM) in the assessment of normovolemia in hemodialysis patients. Contrib Nephrol 2008;161:115-118.

13 Passauer J, Petrov H, Schleser A, Leicht J, Pucalka K: Evaluation of clinical dry weight assessment in haemodialysis patients using bioimpedance spectroscopy: a cross-sectional study. Nephrol Dial Transplant 2010;25:545-551.

14 Machek P, Jirka T, Moissl U, Chamney P, Wabel P: Guided optimization of fluid status in haemodialysis patients. Nephrol Dial Transplant 2010;25:538-544.

15 Hur E, Gungor O, Musayev O, Usta M, Toz H, Asci G, Ozkahya M, Duman S, Ok E: Bioimpedance spectroscopy for the detection of hypervolemia in peritoneal dialysis patients. Adv Perit Dial 2011;27:65-70.

16 Devolder I, Verleysen A, Vijt D, Vanholder R, Van Biesen W: Body composition, hydration, and related parameters in hemodialysis versus peritoneal dialysis patients. Perit Dial Int 2010;30:208-214.

-17 Sipahi S, Hur E, Demirtas S, Kocayigit I, Bozkurt D, Tamer A, Gunduz H, Duman S: Body composition monitor measurement technique for the detection of volume status in peritoneal dialysis patients: the effect of abdominal fullness. Int Urol Nephrol 2011;43:1195-1199.

- 18 Schiller NB, Shah PM, Crawford M, DeMaria A, Devereux R, Feigenbaum H, Gutgesell H, Reichek N, Sahn D, Schnittger I, et al.: Recommendations for quantification of left ventricle by two-dimensional echocardiography. American Society of Echocardiography Committee on Standards, Subcommitee on Quatification of Two-Dimensional Echocardiograms. J Am SocEchocardiogr 1989;2:358-367.

19 Feigenbaum H, Armstrong WF, Ryan T: Evaluation of systolic and diastolic function of the left venticle. In: Feigenbaum H, eds. Feigenbaum's Echocardiography Sixth Edition. Lippincott Williams and Wilkins, Hagerstown, USA; 2005. p142-p145.

20 Lacombe F, Dart A, Dewar E, Jennings G, Cameron J, Laufer E: Arterial elastic properties in man: a comparison of echo-Doppler indices of aortic stiffness. Eur Heart J 1992;13:1040-1045. 


\section{Kidney \\ Blood Pressure Research}

Kidney Blood Press Res 2012;36:268-277

\begin{tabular}{l|l}
\hline DOI: $10.1159 / 000343416$ & (C) 2012 S. Karger AG, Base
\end{tabular}

Published online: November 26, 2012

www.karger.com $/ \mathrm{kbr}$

Sayin/Akpinar/Cetiner/Karabag/Aydin/Hur/Dogan: Aortic Stiffness Predicts Volume Overload in Renal Failure

21 Belz GG: Elastic properties and Windkessel function of the human aorta. Cardiovasc Drugs Ther 1995;9:73-83.

22 Eren M, Gorgulu S, Uslu N, Celik S, Dagdeviren B, Tezel T: Relation between aortic stiffness and left ventricular diastolic function in patients with hypertension, diabetes, or both. Heart 2004;90:37-43.

-23 Mackenzie IS, Wilkinson IB, Cockcroft JR: Assessment of arterial stiffness in clinical practice. QJM 2002;95:67-74.

24 Giachelli CM: Vascular calcification: in vitro evidence for the role of inorganic phosphate. J Am Soc Nephrol 2003;14:S300-S304.

-25 Moe SM, O'Neill KD, Duan D, Ahmed S, Chen NX, Leapman SB, Fineberg N, Kopecky K: Medial artery calcification in ESRD patients is associated with deposition of bone matrix proteins. Kidney Int 2002;61:638-647.

-26 Fukuta H, Ohte N, Mukai S, Asada K, Wakami K, Goto T, Kimura G: Relationship between renal function, aortic stiffness and left ventricular function in patients with coronary artery disease. Circ J 2009;73:17401745.

27 London GM, Marchais SJ, Guerin AP, Metivier F, Adda H: Arterial structure and function in end-stage renal disease. Nephrol Dial Transplant 2002;17:1713-1724.

28 Wizemann V, Schilling M: Dilemma of assessing volume state- the use and limitations of a clinical score. Nephrol Dial Transplant 1995;10:2114-2117.

-29 Leunissen KM, Kouw P, Kooman JP, Cheriex EC, deVries PM, Donker AJ, van Hooff JP: New techniques to determine fluid status in hemodialyzed patients. Kidney Int Suppl 1993;41:S50-S56.

-30 Chamney PW, Wabel P, Moissl UM, Müller MJ, Bosy-Westphal A, Korth O, Fuller NJ: A whole-body model to distinguish excess fluid from the hydration of major body tissues. Am J Clin Nutr 2007;85:80-89.

-31 Churchill DN, Taylor DW, Cook RJ, LaPlante P, Barre P, Cartier P, Fay WP, Goldstein MB, Jindal K, Mandin H, et al.: Canadian hemodialysis morbidity study. Am J Kidney Dis 1992;19:214-34.

32 Stefanadis C, Stratos C, Boudoulas H, Kourouklis C, Toutouzas P: Distensibility of the ascending aorta: comparison of invasive and noninvasive techniques in healthy men and in men with coronary artery

disease. Eur Heart J 1990;11:990-996. 